\title{
Supravalvular pulmonary stenosis as a late complication of surgery for anomalous coronary origin
}

\author{
Diego Martín Raymondi, MD, Sergio Mejía Viana, MD, PhD, Alejandro Berenguel Senén, MD, \\ Jorge Palazuelos Molinero, MD, José Daniel Sáenz de Buruaga, MD, Alejandro Martín Trenor, MD, PhD, and \\ Jesús Herreros González, MD, PhD, Pamplona, Navarre, Spain
}

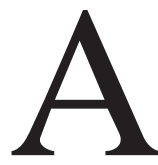

nomalous origin of the left coronary artery from the pulmonary artery (ALCAPA) is a rare cardiac congenital defect. In most such cases the anomalous left coronary artery (ALCA) originates from the left pulmonary sinus, and the clinical picture depends on collateral circulation between both coronary arteries. Pulmonary stenosis has been described as a complication of some surgical approaches to correct this anomaly. In this report we describe this kind of complication in a patient who underwent corrective surgery for this abnormality with a novel technique.

\section{Clinical Summary}

We present the case of a 22 year-old woman. At the age of 4 years, she had undergone corrective surgery for ALCAPA by making an aorta-coronary artery anastomosis using a polytetrafluoroethylene (PTFE)* tubular graft. The coronary edge of the graft was placed inside the pulmonary artery and the proximal edge was anastomosed into aorta after following the anterior wall of the pulmonary artery. She has remained free of overt symptoms since that operation.

During a routine physical examination, an ejective systolic murmur in the left superior sternal border was found. Electrocardiography showed right ventricular hypertrophy, and the echocardiogram demonstrated light left ventricular hypertrophy and a thick, fibrotic pulmonary valve associated with a systolic gradient of $90 \mathrm{~mm} \mathrm{Hg}$. Cardiac catheterization confirmed a supravalvular stenosis at the level of the PTFE graft and also a $50 \%$ to $60 \%$ ostial stenosis of the left coronary artery. Surgery was undertaken to correct these findings. After sternotomy, heart exposure, and cardiopulmonary bypass, a longitudinal incision was made in the pulmonary artery so that the graft was exposed. The graft was still

*Gore-Tex graft; registered trademark of W. L. Gore \& Associates, Inc, Flagstaff, Ariz.

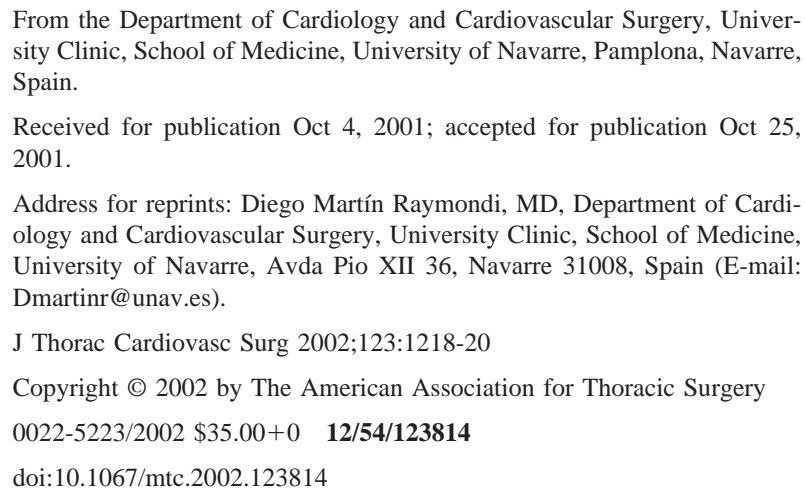

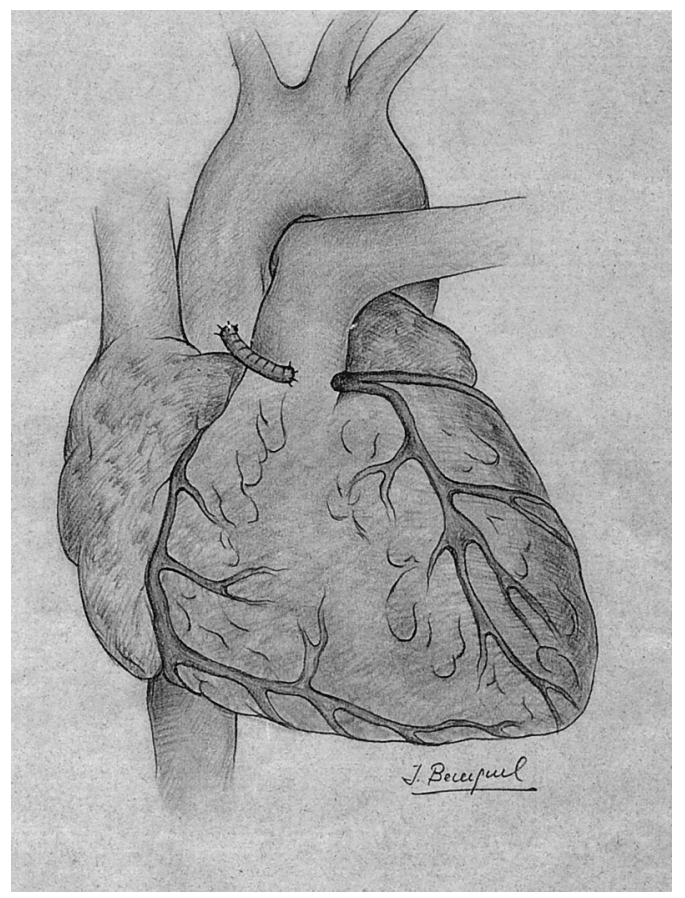

Figure 1. Diagram shows transpulmonary PTFE graft between aorta and ALCA.

permeable but calcified, which had induced an anastomotic stenoses that acted as a banding of the pulmonary artery. The old graft was removed completely, and the coronary artery was disconnected from pulmonary trunk (Figure 1). A newer and longer 6-mm PTFE graft was implanted, with a terminolateral anastomosis between this graft and the aorta. Pulmonary artery incision was amplified with a pericardial patch (Figures 2 and 3). The postoperative outcome was uneventful, and predischarge echocardiography showed a systolic right infundibular dynamic gradient of 32 $\mathrm{mm} \mathrm{Hg}$.

\section{Discussion}

ALCAPA must be surgically corrected even in symptom-free patients, because it carries a high mortality rate when correction is not made in the first year of life, close to $80 \% .{ }^{1}$ Postnatal decrease in pulmonary artery pressure and unsaturated blood flow through the left coronary artery together lead to myocardial ischemia and the beginning of symptoms at an early age, although collateral circulation between both coronary arteries may allow survival through childhood and even into adulthood. Many surgical tech- 

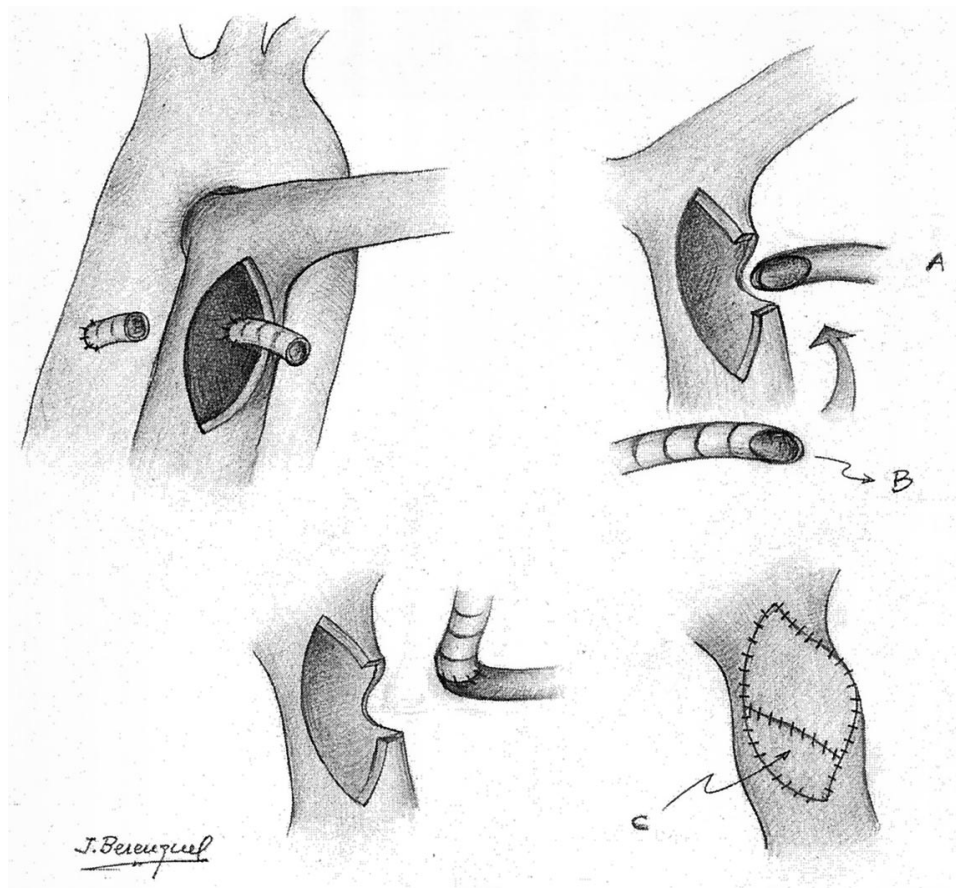

Figure 2. Surgical procedure. $A, A L C A ; B$, PTFE graft; $C$, pericardial patch.

niques for repairing ALCAPA have been described. ${ }^{2}$ When the clinical situation of the infant is critical, ligation of the ALCA must be performed despite its association with higher mortality. Beyond this situation, maintenance of flow through both coronary arteries has to be the aim of treatment. The ideal treatment is direct implantation of the $\mathrm{ALCA}^{3}$ into aorta, although this procedure is technically impossible in most cases because the ALCA usually originates from the left pulmonary sinus. Many other techniques have been reported to achieve the double circulation. At early ages arterial grafts can be made, and bypass techniques with either saphenous vein or thoracic artery can also be used. In the late 1970s and early 1980s, some authors described a few techniques for making a transpulmonary tunnel with pericardial patch, ${ }^{4}$ pulmonary wall (Takeuchi and colleagues ${ }^{5}$ ), or saphenous vein (Arciniegas and associates ${ }^{6}$ ) grafts. Right ventricular outflow tract stenosis has been described as a complication of all these techniques.

In this case the initial management of ALCAPA had involved another procedure. An anastomosis between the ALCA and aorta was made with a PTFE graft. As the vessels grew, the graft became short, producing a banding of the pulmonary artery. To repair these new findings, the technique of Takeuchi and colleagues ${ }^{5}$ was rejected because there was an ostium stenosis of the ALCA, and a saphenous vein graft was not used because of the bad reported results (hyperplasia). We elected not to use a thoracic artery graft in this particular case because the diameter of the thoracic artery was just $1.5 \mathrm{~mm}$, just half the $3-\mathrm{mm}$ diameter of the ALCA. Considering the results of the old graft, we decided to use a new PTFE graft to make the newer connection between the aorta and

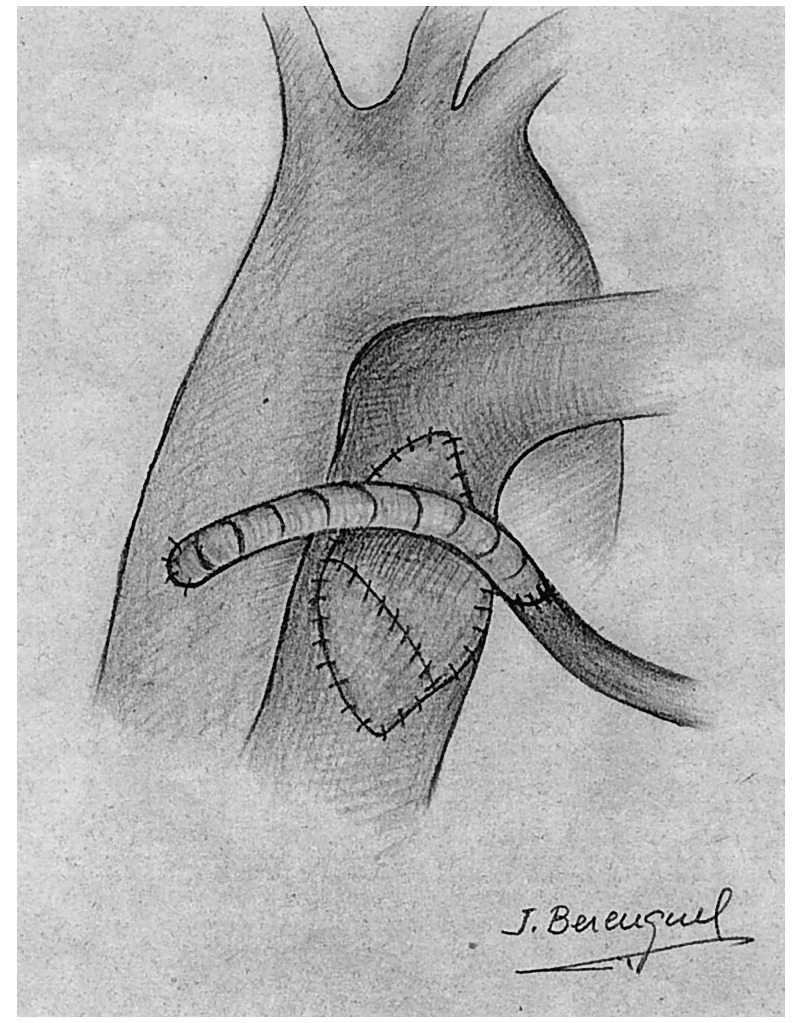

Figure 3. Final anastomosis between aorta and ALCA with PTFE graft. Note pericardial patch on pulmonary artery. 
the ALCA. This is the first time that a PTFE graft bypass has been described and also the first time that right ventricular outflow stenosis has been reported with this technique.

We thank Dr Barba for his echocardiographic guidance and Juan Berenguel for his outstanding drawings.

\section{References}

1. Keith JD. The anomalous origin of the left coronary artery from pulmonary artery. Br Heart J. 1959;21:149-61.

2. Backer CL, Stout MJ, Zales VR, Muster AJ, Weigel TJ, Idriss FS, et al. Anomalous origin of left coronary artery: a twenty-year review of surgical management. J Thorac Cardiovasc Surg. 1992; 103;1049-58.

3. Wollenek G, Domanig E, Salzer-Muhar U, Havel M, Wimmer M, Wolner E. Anomalous origin of left coronary artery: a review of surgical management in 13 patients. J Cardiovasc Surg. 1993;34:399-405.

4. Hamilton DI, Ghosh PK, Donnelly RJ. An operation for anomalous origin of left coronary artery. Br Heart J. 1979;41:121-4.

5. Takeuchi S, Imamura H, Katsumoto K, Hayashi I, Katohgi T, Okura M, et al. New surgical method for repair of anomalous left coronary artery from pulmonary artery. $J$ Thorac Cardiovasc Surg. 1979;78:7-11.

6. Arciniegas E, Farooki ZQ, Hakimi M, Green EW. Management of anomalous left coronary artery from the pulmonary artery. Circulation. 1980;60(2 Pt 2):I180-9.

\section{Notice from the American Board of Thoracic Surgery regarding trainees and candidates for certification who are called to military service related to the war on terrorism}

The Board appreciates the concern of those who have received emergency call to military service. They may be assured that the Board will exercise the same sympathetic consideration as was given to candidates, in recognition of their special contributions to their country, during the Viet Nam conflict and the Persian Gulf conflict with regard to applications, examinations, and interruption of training. If you have any questions about how this might affect you, please call the Board office at 847-475-1520.

Peter C. Pairolero, MD

The American Board of Thoracic Surgery 